\title{
BUDIDAYA RUMPUT LAUT DI PANTAI BOLOK KUPANG - NUSA TENGGARA TIMUR
}

\author{
Priska Gardeni Nahak $^{1}$, Diarto Trisnoyuwono ${ }^{2}$
}

\begin{abstract}
:
NTT Province as one of the provinces in Indonesia has many islands, with the main livelihood of the people were farming, gardening and seaweed farmers. One of the flagship products of seafood NTT was seaweed. Kupang district is one of the producers of seaweed in the province, but the availability of area for those matter until now not able to meet the maximum target of dry seaweed. Additionally dried seaweed produced has poor quality because it still contains a lot of impurities, thus affecting the selling price, which would certainly have an impact on the income and welfare of the farmers. It is because the technique that applied to both the cultivation technique and drying techniques were still very traditional.

One of the technologies offered to overcome those problems was 'Dryer Box Technology'. This technology were expected especially to minimize the amount of seaweed ready for harvest were always broken and lost in the rainy season, due to lack of seaweed dryers facilities. In addition by these technology were also expected to get more cleaner dried seaweed because it is not contaminated with dirt when drying, so as to improve the quality of the dried seaweed. This quality improvement, also will increase the selling price of which would increase the income and welfare of farmers seaweed, as well as increasing the amount of seaweed production in NTT Province.

The dryer box technology has a dimension $0.8 \mathrm{~m}$ lenght; $0.66 \mathrm{~m}$ width; and $1.5 \mathrm{~m}$ height. so that for once the drying process, $50 \mathrm{~kg}$ of wet grass only requires about $0.53 \mathrm{~m}^{2}$ of area, while using traditional drying methods requires $10 \mathrm{~m}^{2} \pm \mathrm{s} / \mathrm{d} 15 \mathrm{~m}^{2}$ of area depending on the number of wet grass. Besides shorter drying time is for $50 \mathrm{~kg}$ of wet grass, it takes only about \pm 0.75 hours. Whereas with traditional systems, drying time takes an average of 3-4 days. This will increase the productivity of dry seaweed, which can increase the production quantity of dried seaweed ready though in NTT Province.
\end{abstract}

Keywords : Dryer box, Dried seaweed, Culvitable product.

\section{PENDAHULUAN}

Rumput laut atau sea-weeds secara ilmiah dikenal dengan istilah alga atau ganggang yang berklorofil. Istilah "rumput laut" sebenarnya kurang tepat karena secara botani alga tidak termasuk golongan rumput-rumputan (graminae). Istilah lain adalah agar-agar, merupakan sebutan untuk jenis alga karena kandungan kimianya.
Secara umum, perairan di Indonesia terdapat / hidup rumput laut, baik yang sengaja ditanam atau hidup secara alamiah. Lebih dari 50 spesies rumput laut dapat dimanfaatkan untuk konsumsi. Di Sulawesi, Maluku dan Nusa Tenggara, banyak dikembangbiakkan untuk kebutuhan utama sebagai bahan makanan atau sebagai bahan tambahan untuk industri makanan, farmasi, kosmetik, tekstil, kertas, cat dan lainlain. Selain itu digunakan pula sebagai pupuk 
hijau dan komponen pakan ternak maupun ikan agar-agar adalah jenis gracilaria verrucosa.

Rumput laut (seaweed) dibudidayakan hampir diseluruh wilayah Nusa Tenggara Timur (NTT). Produksinya terus meningkat dari tahun ketahun. Untuk tahun 2007 para pengusaha NTT mengantarpulaukan rumput laut yang kering sebanyak 47.088 ton, dengan nilai 235,4 miliar rupiah. Sedangkan pada tahun 2008 mencapai 82.992,05 ton (http://www.nttprov.go.id/ ntt_09, 28 Maret 2012). Budidaya rumput laut sangat didukung oleh kondisi NTT yang daerah perairan pantai sangat luas. Fakta lainnya menunjukkan bahwa NTT merupakan Propinsi kepulauan yang terdiri dari 566 pulau besar dan kecil, 42 pulau telah bernama dan 524 pulau belum bernama (Propada, 2001). Perairan laut NTT sangat cocok dibudidayakan rumput laut. Daerah ini dapat dibudidayakan 14 jenis rumput laut (Aslan M. Laode, 1998).

Ketika semakin luasnya pemanfaatan hasil olahan rumput laut dalam berbagai industri, maka semakin meningkat pula kebutuhan akan rumput laut Eucheuma sp sebagai bahan baku. Selain untuk kebutuhan ekspor, pangsa pasar dalam negeri cukup penting karena selama ini industri pengolahan rumput laut sering mengeluh kekurangan bahan baku. Khususnya produksi rumput laut di NTT hingga saat ini belum dapat memenuhi kebutuhan pasar nasional baik dari sisi kualitas maupun kuantitas. Diantara penyebab belum maksimalnya hasil produksi rumput laut masyarakat adalah teknik pengeringan yang belum efektif dan efisien.

Umumnya teknik pengeringan yang digunakan saat ini adalah dengan cara tradisional yaitu menghamparkan rumput basah di atas para-para atau di atas tanah/tumpukan batu baik dengan alas berupa waring maupun tanpa alas. Tehnik ini banyak dipakai karena mudah dan murah.Namun dari sisi kualitas sangat berpengaruh, di mana rumput laut kering yang dihasilkan memiliki mutu yang kurang baik karena banyak mengandung material lain seperti batu, tanah maupun sampah lainnya. Menurut Aslan M Laode, 1998, mengatakan, "Penurunan kualitas rumput laut dikarenakan adanya benda asing (garam, pasir, karang, daun-daun dan kayu) yang melekat pada rumput laut". Akibatnya harga jual rumput laut kering dari para petani tersebut mengalami penurunan (Pos Kupang, 1 Maret 2009) "Rumput laut di Kabupaten Manggarai Barat mengalami penurunan harga. Hal ini dikarenakan kualitasnya yang kurang baik".

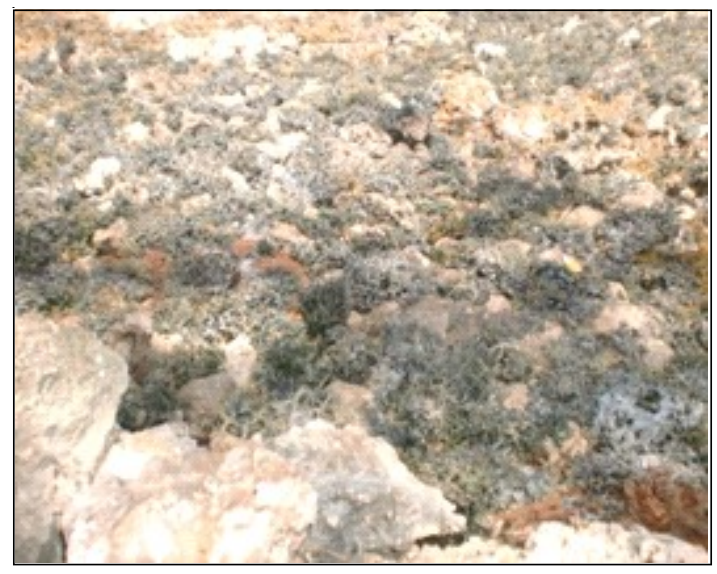

Gambar 1. Cara pengeringan rumput laut di lokasi mitra yaitu dengan menghampar rumput laut di atas tumpukan batu, tanpa alas

Dari sisi Kuantitas, terlihat bahwa dengan system tradisional, pada saat penjemuran banyak rumput laut kering yang terbuang percuma, karena banyak bagian rumput kering, terutama bagian yang kecil-kecil akan tertinggal saat diangkut karena banyak yang masuk ke lubang-lubang batu maupun tercampur dengan tanah/sampah sehingga tidak terlihat. Akibatnya jumlah rumput laut kering yang dikumpulkan menjadi berkurang.

Selain itu dengan system tradisional ini, petani hanya bisa menjemur rumput lautnya pada saat musim panas, sedangkan pada musim hujan petani tidak dapat menjemur rumput lautnya lagi. Akibatnya pada musim hujan, banyak rumput laut siap panen yang tetap dibiarkan di laut, yang akhirnya rusak atau terlepas dan hilang terbawa arus. Oleh sebab itu diperlukan suatu teknologi tepat guna untuk dapat menanggulangi permasalahan yang dihadapi para petani rumput laut tersebut. 


\section{JUTEKS Jurnal Teknik Sipil}

Salah satu teknologi yang ingin diterapkan adalah "Teknik Kotak Pengering". Teknologi ini berupa rak-rak dalam kotak yang dilengkapi dengan system pemanas dengan bahan bakar yang murah dan mudah diperoleh yaitu kayu bakar atau minyak tanah, sehingga dapat mengeringkan rumput laut, bahkan pada musim hujan sekalipun. System kotak pengering ini juga dapat mempersingkat waktu pengeringan, dimana jika dengan system tradisional paling sedikit dibutuhkan 3 hari untuk pengeringan, namun dengan system kotak pengering, waktu yang diperlukan hanya sekitar $\pm 0,75 \mathrm{jam}$. Dari sisi kualitas, rumput laut kering yang dihasilkan melalui kotak pengering, memiliki mutu yang jauh lebih baik dari rumput laut yang dikeringkan melalui system tradisional, karena tidak terkon-taminasi oleh sampah selama pengeringan, sehingga lebih bersih dan memiliki kualitas yang lebih baik.

Teknik ini ditawarkan dengan harapan dapat mengatasi permasalahan yang dihadapi oleh para petani rumput laut, terutama meminimalisir jumlah rumput laut siap penen yang selalu rusak dan hilang pada musim penghujan. Hal ini dengan sendirinya akan meningkatkan pendapatan para petani rumput laut, dan juga meningkatkan jumlah dan mutu produksi rumput laut NTT.

Yang menjadi sasaran UMKM dalam rencana kegiatan ini adalah kelompok usaha rumput laut di Desa Kuanheun yaitu Kelompok usaha "Pantai Susan" (10 petani) dan Kelompok usaha Oeli'i Indah (10 Orang). Umumnya para petani ini memulai usahanya dari tahun 2000 dengan hasil produksi rata-rata pertahun $50-70$ ton / kelompok. Wilayah ini memiliki lahan potensial untuk rumput laut seluas $\pm 450 \mathrm{Ha}$, namun dengan keterbatasan lahan pengeringan, maka banyak rumput laut siap panen yang terpaksa dibiarkan di laut, untuk mengantri lahan yang aktif digunakan untuk pengeringan/penjemuran.

Kelompok ini dipilih sebagai mitra dalam penerapan Ipteks karena beberapa hal yang melatarbelakanginya, yaitu antara lain :
1.Adanya dukungan penuh dari Pemerintah Daerah setempat dan dinas-dinas terkait untuk mengembangkan budidaya rumput laut sebagai produk unggulan daerah.

2.Menjadikan kelompok-kelompok ini sebagai pilot project untuk dicontohi wilayah-wilayah lain di Kabupaten Kupang dan NTT secara umum.

3.Wilayah yang luas dan jumlah petani yang tergabung dalam beberapa kelompok memungkinkan diupayakannya penerapan teknologi kotak pengering untuk meningkatkan hasil produksi.

4.Organisasi kelompok yang cukup baik dan rasa kebersamaan yang terjalin dalam kelompok untuk mengembangkan usaha mereka dirasakan akan mendukung proses pengembangan usaha mereka apabila teknologi terapan ini dapat semakin meningkatkan hasil panen rumput laut dan sekaligus dikembangkan.

Selanjutnya dapat diidentifikasi sejumlah masalah Mitra yang perlu diangkat dalam kegiatan Penerapan IPTEKS ini adalah :

1). Metode pengeringan rumput laut yang digunakan oleh Mitra saat ini masih tergolong tradisional, sehingga kurang efektif dan efisien, sehingga hasil yang diperoleh kurang maksimal; 2). Banyak rumput laut siap panen yang terpaksa dibiarkan di laut karena ketiadaan lahan pengering sehingga harus mengantri untuk dikeringkan, atau karena musim hujan sehingga tidak ada matahari untuk mengering-kan rumput laut tersebut, akibatnya banyak rumput laut siap panen banyak yang rusak atau terlepas dan hanyut dibawa arus laut; 3). Rumput laut kering yang dihasilkan oleh Mitra banyak mengandung kotoran baik berupa sampah, tanah maupun batu, sehingga mempengaruhi harga jual rumput laut kering oleh petani.

Teknologi kotak pengering yang dibuat memiliki spesifikasi sebagai berikut :

a.Panjang, dan lebar : 0,8 x 0,66 m

b. Tinggi $: 1,5 \mathrm{~m}$ 

c. Bahan bakar
: Arang kayu atau kompor minyak tanah
d.Rangka : Aluminium profil
e.Dinding kotak : Plat Aluminium

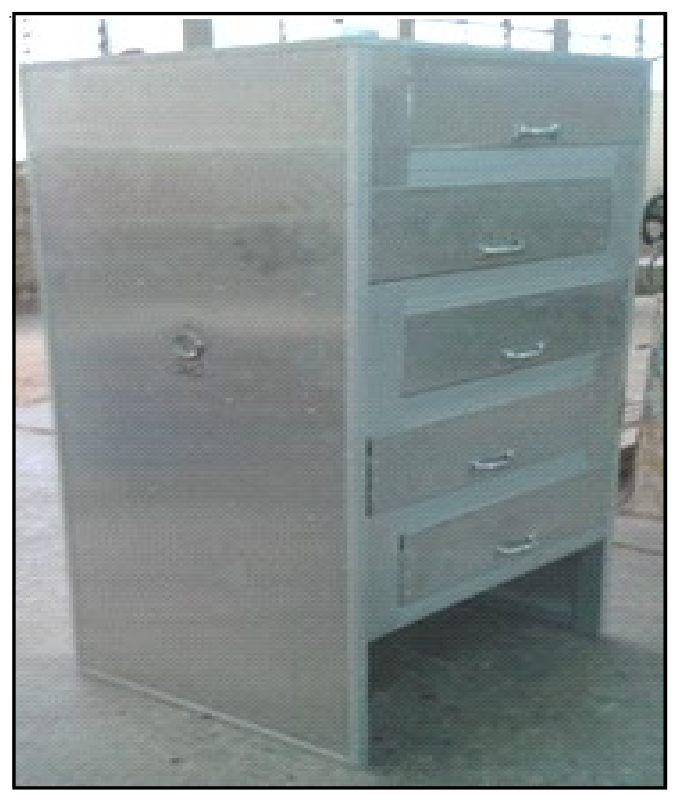

Gambar 2. Model Kotak Pengering Rumput Laut

\section{METODE PELAKSANAAN}

Metode dan tahapan pengabdian yaitu meliputi,

1.Tahap observasi dan penyiapan wilayah binaan.

Tahapan ini untuk meninjau kesiapan lokasi dan mitra nelayan untuk aplikasi teknologi pengering apung. Termasuk mengurus perijinan dengan pihak-pihak terkait.

2.Tahap pengumpulan bahan.

Tahap ini untuk menyiapkan bahan-bahan untuk keperluan konstruksi kotak pengering dan persiapan fasilitas kerja untuk produksi kotak pengering.

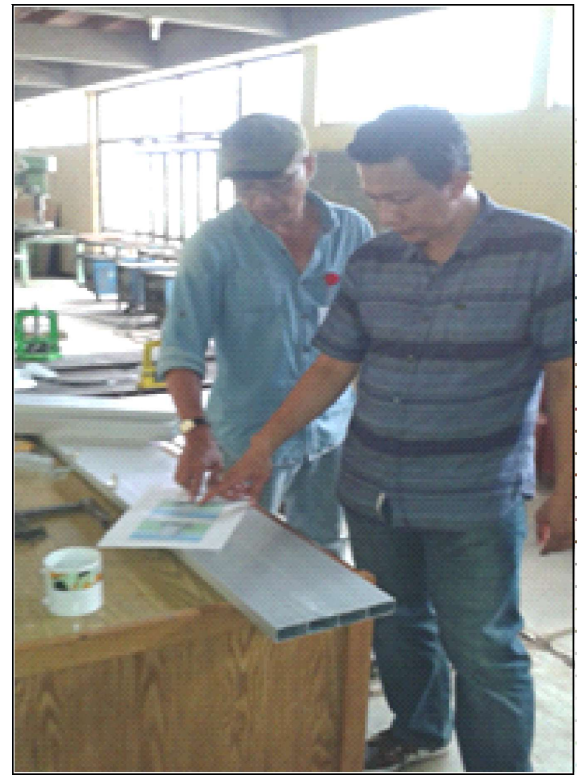

Gambar 3. Persiapan \& penyiapan bahan

3.Tahap pembuatan kotak pengering.

Aktivitas pembuatan kotak pengering dilakukan di fasilitas workshop konstruksi jurusan teknik sipil Politeknik Negeri Kupang. Ketersediaan peralatan yang lengkap diharapkan dapat membantu terlaksananya pekerjaan ini.

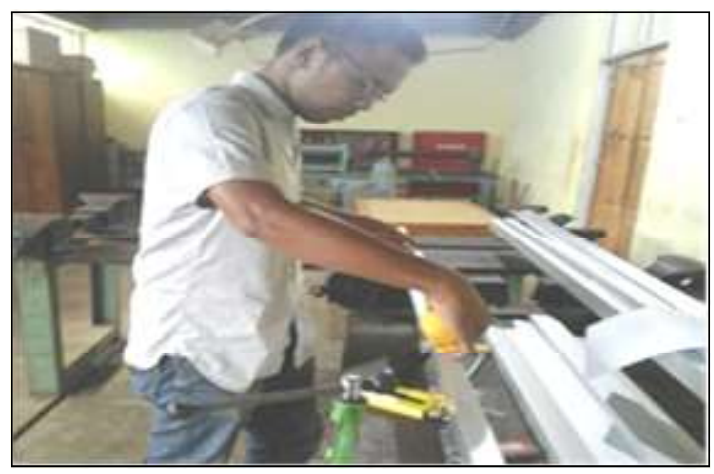

Gambar 4. Proses Konstruksi Rumpon

\section{Tahap uji coba pengering apung.}

Konstruksi pengering apung dibawa ke lokasi binaan untuk diuji coba aplikasinya di kawasan budidaya rumput laut. Sekaligus penebaran benih untuk pertama kali dan selanjutnya akan diobservasi tingkat keberhasilan jenis konstruksi ini selama 4 bulan. 


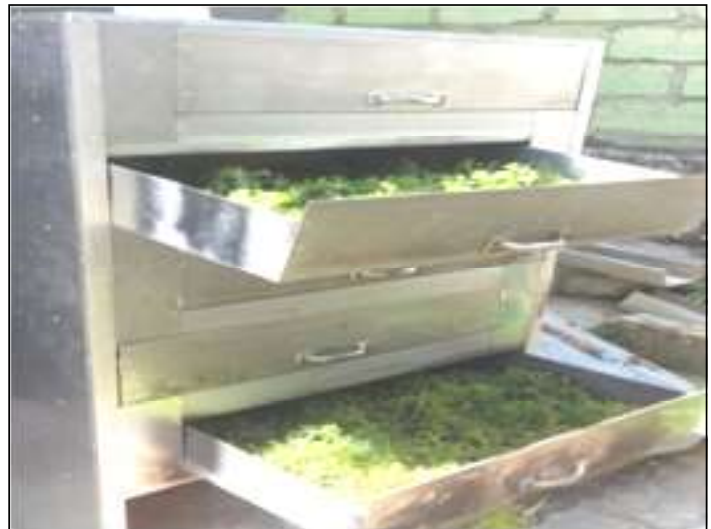

Gambar 5. Tahap uji coba 1

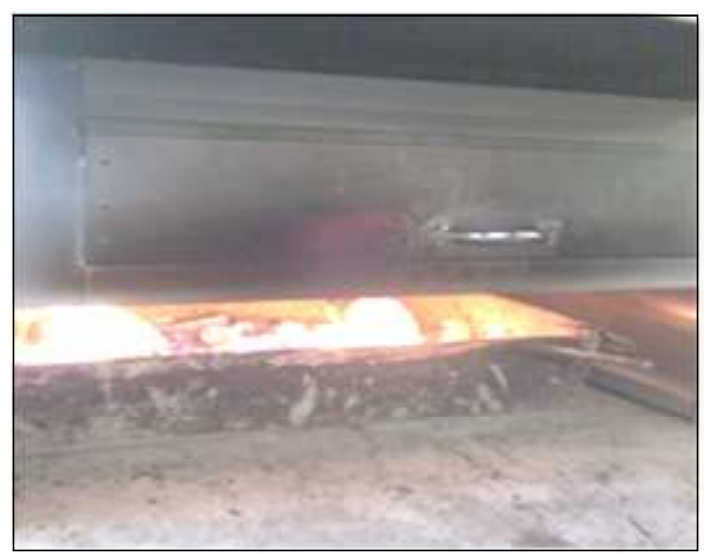

Gambar 6. Tahap uji coba 2

\section{Tahap transfer teknologi}

Kelompok nelayan yang menjadi mitra akan diberi pembinaan secara berkala untuk dapat membuat sendiri kotak pengering, dimulai dari cara pemilihan bahan baku, cara pembuatan sampai dengan cara pemeliharaannya. Nelayan mitra juga akan diberi penyuluhan untuk teknik pengeringan dan cara menghasilkan rumput laut kering sesuai standar nasional.

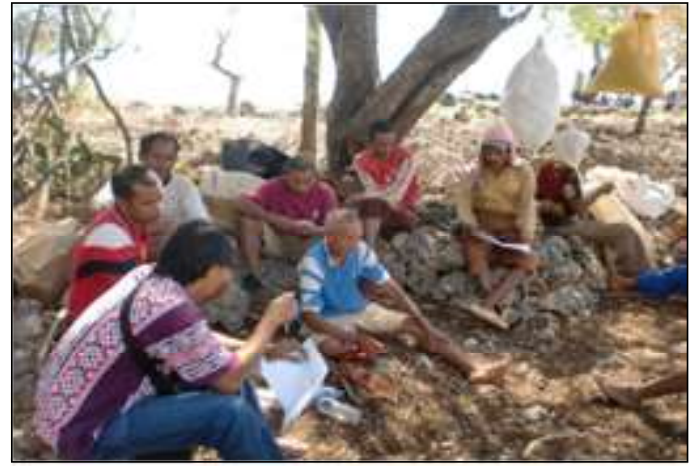

Gambar 7. Penyuluhan Kepada Mitra

\section{HASIL DAN PEMBAHASAN}

Hasil yang telah dicapai dalam kegiatan ini adalah pembuatan kotak pengering rumput laut sebanyak 1 (satu) unit. Dari bahan baku yang ada, kemudian dilakukan perakitan di fasilitas laboratorium konstruksi jurusan teknik sipil Politeknik Negeri Kupang.

Secara detail keuntungan yang dapat diperoleh adalah:

1.Teknik kotak pengering ini membutuhkan luasan yang jauh lebih kecil dari teknik tradisional. Ukuran kotak pengering yang dipakai adalah panjang $0,8 \mathrm{~m}$, lebar $0,66 \mathrm{~m}$ dan tinggi $1,5 \mathrm{~m}$ yang berisi 5 (lima) rak. Maka untuk sekali proses pengeringan, $50 \mathrm{~kg}$ rumput basah hanya membutuhkan luasan $0,53 \mathrm{~m}^{2}$, jika dibandingkan dengan teknik pengering tradisional untuk penjemuran biasanya membutuhkan lahan seluas $10 \mathrm{~m}^{\mathbf{2}}$ atau $15 \mathrm{~m}^{\mathbf{2}}$ tergantung jumlah rumput basah.

2. Waktu pengeringan yang lebih singkat yaitu untuk $50 \mathrm{~kg}$ rumput basah, hanya diperlukan waktu sekitar 0,75 jam. Sedangkan dengan sistem tradisional, waktu pengeringan yang diperlukan rata-rata $3-4$ hari. Hal ini berarti tingkat produktivitas rumput laut kering akan menjadi lebih tinggi.

3. Sumber panas memanfaatkan bara api dari arang kayu, limbah kayu hasil pengolahan ataupun kompor minyak, sehingga hemat energi.

4.Kotak pengering berupa rak-rak yang berfungsi sebagai tempat pengering dengan 
bahan dasar untuk rangka kotak pengering terbuat dari aluminium profil dan dinding serta bahan rak terbuat dari aluminium sehingga bobotnya ringan, mudah menyalurkan panas dan tidak mudah berkarat. Hal ini memungkinkan petani untuk tetap dapat mengeringkan rumput lautnya, walau pada musim hujan sekalipun.

5.Karena proses pengeringan dilakukan dalam kotak tertutup, sehingga rumput kering yang dihasilkan lebih bersih karena tidak terkontaminasi oleh sampah. Hal ini berarti bahwa rumput laut kering yang dihasilkan ini memiliki mutu yang jauh lebih baik dari rumput laut kering system tradisional, sehingga diharapkan dapat meningkatkan harga jualnya. Jika harga jualnya meningkat, maka diharapkan dapat meningkatkan pendapatan dan produktivitas dari petani rumput laut.

\section{KESIMPULAN}

1.Pembuatan fasilitas kotak pengering rumput laut sebanyak 1 (satu) unit telah dilakukan dengan adanya penyesuaian terhadap jenis bahan baku.Ukuran kotak pengering yang dipakai adalah panjang $0,8 \mathrm{~m}$, lebar $0,66 \mathrm{~m}$ dan tinggi 1,5 m yang berisi 5 (lima) rak dan sumber panas (arang kayu).
2.Kotak pengering rumput laut terbukti efektif dan efisien dengan daya tampung $50 \mathrm{~kg}$ rumput laut basah, dengan waktu pengeringan yang lebih singkat yaitu hanya diperlukan waktu sekitar 0,75 jam. Kotak pengering ini juga dapat dimanfaatkan untuk membuat ikan panggang, daging panggang, mengeringkan kopra dan kebutuhan pengolahan bahan makanan lainnya.

3.Pelatihan singkat tentang teknik pembuatan dan pemeliharaan kotak pengering dilakukan, agar mitra dapat membuat dan merawat sendiri alat pengeringnya. Sehingga diharapkan dapat meningkatkan hasil produksi rumput laut.

\section{DAFTAR PUSTAKA}

Cholik, F. 1991. Budidaya rumput laut Eucheuma Sp dengan pengering dan lepas dasar. Pusat Penelitian dan Pengembangan Perikanan, Badan Litbang Pertanian, Jakarta.

Flores Pos, edisi 16 April 2004, Potensi Laut NTT Yang Melimpah.

Ismail, W, 1992. Budidaya rumput laut jenis algae merah. Makalah Aplikasi Teknologi Kupang NTT, 2-3 Maret 1992. 